\title{
A review and survey of policies utilized for interventional pain procedures: a need for consensus
}

This article was published in the following Dove Press journal: Journal of Pain Research

17 March 2017

Number of times this article has been viewed

\author{
Lynn Kohan' \\ Reza Salajegheh' \\ Robin J Hamill-Ruth' \\ Sandeep Yerra' \\ John Butz ${ }^{2}$ \\ 'Department of Anesthesiology, \\ University of Virginia, Charlottesville, \\ VA, ${ }^{2}$ West River Anesthesiology \\ Consultants, Rapid City, SD, USA
}

Correspondence: Sandeep Yerra Department of Anesthesiology, University of Virginia, PO Box 8007I0, Charlottesville, VA 22908-0710, USA

Tel + I 4349242283

Fax +l 4349820019

Email drsandeepyerra@gmail.com
Background: Other than the newly published anticoagulation guidelines, there are currently few recommendations to assist pain medicine physicians in determining the safety parameters to follow when performing interventional pain procedures. Little information exists regarding policies for oral intake, cumulative steroid dose limits, driving restrictions with and without sedation, and routine medication use for interventional procedures.

Methods: A 16-question survey was developed on common policies currently in use for interventional pain procedures. The questionnaire was distributed through the American Society of Regional Anesthesia and Pain Medicine and American Academy of Pain Medicine. We sought to statistically analyze the range of policies being used by pain medicine physicians and to determine if there are any commonly accepted standards. Results: A total of 337 physicians out of 4037 members responded to our survey with a response rate of $8.4 \%$. A total of $82 \%$ of these respondents used a sedative agent while performing an interventional pain procedure. The majority of respondents required drivers after procedures, except after trigger points. A total of $47 \%$ indicated that they have an nil per os (NPO) policy for procedures without sedation. A total of $98 \%$ reported that they had an anticoagulation policy before an interventional procedure. A total of $17 \%$ indicated that the interval between steroid doses was $<2$ weeks, while $53 \%$ indicated that they waited 2-4 weeks between steroid doses.

Conclusion: Our study has clearly demonstrated a wide variation in the current practice among physicians regarding sedation, NPO status, steroid administration, and the need for designated drivers. There was much higher endorsement of policies regarding anticoagulation. There is an obvious need for evidence-based guidelines for these aspects of interventional pain care to improve patient safety and minimize the risk of adverse events.

Keywords: interventional pain procedures policies, steroids in pain procedures, driver policy in interventional pain procedures, NSAIDs and anticoagulants in interventional pain procedures

\section{Aim}

The aim of this study was to assess the range of current safety practices implemented by interventional pain medicine physicians across USA through a 16-question survey.

\section{Introduction}

There are currently few guidelines to assist pain medicine physicians in determining the best safety practices to follow when performing interventional pain procedures. Recent guidelines advocated by the American Society of Regional Anesthesia (ASRA) address anticoagulation. ${ }^{1}$ The American Society of Anesthesiologists (ASA) suggested in 2010 that minor pain procedures, under most routine circumstances, do not require 
anesthesia care other than local anesthesia. ${ }^{2}$ We found little information regarding recommendations for restrictions on oral intake prior to interventional pain procedures, cumulative steroid dose limits and timing of dosing, driving restrictions with and without sedation, or routine medication use prior to interventional procedures. The recent ASRA guidelines address nonsteroidal anti-inflammatory drugs (NSAIDs), as well as garlic, gon quai, danshen, ginkgo bilboa, and panaz ginseng. We attempted to statistically analyze the practices, which were reported by pain medicine physicians, and to determine if there was any uniformity in such safety policies or commonly accepted standards specifically related to interventional pain procedures. Also included in the survey was the rate at which steroids are being utilized in various interventional pain procedures and how often policies addressed limiting the frequency of dose or intervals between doses.

\section{Methods}

A 16-question survey was developed on common practices currently in use before an interventional pain procedure (Supplementary material). The questions addressed NPO status, cessation of anticoagulants, use of sedation, and the driver policy for sedated patients versus nonsedated patients. Corticosteroid use among the most common interventional pain procedures was assessed using the time intervals between repeated doses. The survey was hosted on the Internet through SurveyMonkey ${ }^{\mathrm{TM}}$. The questionnaire was dispersed through the following two professional organizations that agreed to assist with this study by forwarding the SurveyMonkey ${ }^{\mathrm{TM}}$ link to their membership: ASRA and Pain Medicine and American Academy of Pain Medicine. This survey was dispersed to all the members of the above organizations. The survey was open 212 days, and no compensation was given for completing the survey. Since this survey did not involve any identifiable patient information or a clinical investigation, consent was implied with a voluntary return of the completed survey. The results were analyzed and are reported in simple descriptive statistics.

\section{Results}

A total of 337 physicians responded to the survey. Results from 41 respondents were not included because they did not complete the entire survey questionnaire.

\section{Use of sedation}

A total of $82 \%$ of respondents used a sedative agent while performing an interventional pain procedure. The use of sedation depended on the type of procedure being performed. Sedation was used in $80 \%$ of the patients for radiofrequency ablation procedures, $66 \%$ of the patients for sympathetic blocks, $54 \%$ of the patients for epidural steroid procedures, $50 \%$ of the patients for medial branch nerve blocks, $43 \%$ of the patients for regional nerve blocks (ilioinguinal/iliohypogastric, femoral, supraclavicular, and so on), $42 \%$ of the patients for sacroiliac joint injections, $30 \%$ of the patients for superficial peripheral blocks (occipital, supraorbital, and so on), $20 \%$ of the patients for intraarticular nerve blocks, and 5\% of the patients for trigger point injections.

The most commonly used class of drugs for sedation was benzodiazepines, reported by $97 \%$ of the participants. Opioids were administered by $77 \%$ of the respondents, $\mathrm{N}$-methyl-d-aspartate (NMDA) receptor antagonists were administered by $15 \%$ of the respondents, antihistamines were administered by $7 \%$ of the respondents, and alpha- 2 agonists were administered by $7 \%$ of the respondents. Of note, propofol was used by $36 \%$ of the respondents. Linkage between specific procedures and sedatives was not sought in an effort to limit the duration of the survey.

\section{Driver policy}

The majority of respondents required drivers after procedures, except after trigger points. Procedures involving local anesthetic were more likely to require a designated driver. However, not all respondents required drivers even if the procedure could be associated with risks such as sympathectomy and motor blockade. The addition of sedation consistently increased the requirement of a designated driver, yet this was still not $100 \%$. The differences on driver policy based on the type of procedure without and with the use of sedation are listed in Tables 1 and 2, respectively.

\section{Policies regarding timing of corticosteroid doses}

Participants were asked if there was a minimal time interval between the administrations of corticosteroids. A total of $82 \%$ indicated that there was a time interval. A total of $17 \%$ indicated that the interval was $<2$ weeks, while $53 \%$ indicated that they waited 2-4 weeks between steroid doses. A total of $30 \%$ of the physicians also indicated waiting more than a month between two successive exposures. Steroid use for different procedures is reported in Table 3.

\section{Aspirin or other antiplatelet medications}

Wide variations were seen in the length of time patients were asked to hold their antiplatelet medication or aspirin before an interventional pain procedure. A total of $67 \%$ respondents 
Table I Driver practices for patients not receiving sedation

\begin{tabular}{llll}
\hline Procedure & Designated driver (\%) & Public transportation (\%) & Self-drive (\%) \\
\hline Epidural injection with local anesthetic & 85 & 2 & 13 \\
Epidural injection without local anesthetic & 60 & 5 & 35 \\
Diagnostic medial branch blocks & 62 & 3 & 35 \\
Sacroiliac joint injection & 60 & 4 & 36 \\
TPls & 19 & 4 & 77 \\
Regional nerve blocks & 81 & 2 & 17 \\
Plexus/ganglion blocks & 91 & 2 & 7 \\
\hline
\end{tabular}

Abbreviation: TPls, trigger point injections.

Table 2 Driver policy for patients receiving sedation

\begin{tabular}{llll}
\hline Procedure & Designated driver (\%) & Public transportation (\%) & Self-drive (\%) \\
\hline Epidural injection with local anesthetic & 99 & 0 & $\mathrm{I}$ \\
Epidural injection without local anesthetic & 97 & $\mathrm{I}$ & 2 \\
Diagnostic medial branch blocks & 97 & $\mathrm{I}$ & 2 \\
Sacroiliac joint injection & 90 & 3 & 7 \\
Trigger point injections & 97 & $\mathrm{I}$ & 2 \\
Regional nerve blocks & 97 & 2 & $\mathrm{I}$ \\
Plexus/ganglion blocks & 98 & $\mathrm{I}$ & $\mathrm{I}$ \\
\hline
\end{tabular}

Table 3 Procedures utilizing steroids and frequency of their use

\begin{tabular}{llll}
\hline Procedure & $\begin{array}{l}\text { Never } \\
\text { (\%) }\end{array}$ & $\begin{array}{l}\text { Rarely } \\
\text { (\%) }\end{array}$ & $\begin{array}{l}\text { Often } \\
\text { (\%) }\end{array}$ \\
\hline Trigger point injections & 30 & 28 & 42 \\
Regional blocks & 37 & 33 & 30 \\
Peripheral nerve blocks & 27 & 29 & 43 \\
Interlaminar epidural steroid injections & 4 & 3 & 93 \\
Transforaminal epidural steroid injections & 4 & 3 & 93 \\
Medial branch nerve blocks & 43 & 27 & 30 \\
Intraarticular (including facet) injections & 5 & 4 & 91 \\
Sacroiliac joint injections & 4 & 1 & 94 \\
Radiofrequency ablation & 32 & 22 & 46 \\
Plexus/ganglion blocks & 35 & 32 & 32 \\
\hline
\end{tabular}

did not have a policy to hold aspirin before an interventional pain procedure. The length of time that aspirin was held in relation to procedures is listed in Table 4.

A total of $70 \%$ of the physicians in the survey reported that they did not ask patients to hold their NSAIDs prior to an injection. Among those who did ask patients to hold NSAIDs, the length of time that the NSAIDs were held depended on the type of procedure being performed (Table 5).

\section{Anticoagulants}

Highest consensus was found in regard to anticoagulants, such as heparin, enoxaparin, and warfarin. A total of $98 \%$ of the respondents indicated that they asked their patients to stop these anticoagulants before an interventional pain procedure.

Medications, such as selective serotonin reuptake inhibitors (SSRIs), serotonin-norepinephrine reuptake inhibitors (SNRIs), and herbal medications, were not held by $73 \%$ of the respondents. For those who did hold SNRIs and SSRIs, specifics were not sought regarding procedures or duration of that hold.

\section{Nil per os (NPO) policy}

A total of $47 \%$ of the physicians indicated that they have an NPO policy in procedures without sedation. In patients receiving sedation for procedures, a majority $(90 \%)$ indicated that they have a policy.

\section{IRB approval}

IRB approval is not needed. This study was determined to not meet the criteria of research with human subjects or a clinical investigation and, therefore, is not subject to Institutional Review Board for Health Sciences Research (IRB-HSR) review (University of Virginia's IRB-HSR tracking number with IRB exempt status - 19622).

\section{Discussion}

Currently, few best practice guidelines exist to assist interventional pain physicians with periprocedural care. While anesthesiology has established guidelines for monitoring the anesthesia care, these guidelines have not been embraced by the multidisciplinary pain medicine community. ${ }^{3}$ Our survey found that there is a wide variation in the safety policies related to oral intake, designated drivers, use of sedation, and medication use that are used by the responding physicians providing interventional pain care. This variation may potentially be due to the lack of established guidelines specifically for interventional pain procedures, 
Table 4 Length of time aspirin was held based on the type of procedure

\begin{tabular}{|c|c|c|c|}
\hline Procedure & $\begin{array}{l}\text { Held on day of } \\
\text { procedure (\%) }\end{array}$ & $\begin{array}{l}\text { Held }<\text { I week prior } \\
\text { to the procedure }(\%)\end{array}$ & $\begin{array}{l}\text { Held }>\text { I week prior } \\
\text { to the procedure (\%) }\end{array}$ \\
\hline TPls & 70 & 20 & 10 \\
\hline Medial branch block & 27 & 48 & 21 \\
\hline Cervical epidural steroid injections & 8 & 39 & 50 \\
\hline Lumbar epidural steroid injections & 10 & 43 & 19 \\
\hline Joint injections & 39 & 41 & 19 \\
\hline Peripheral nerve blocks & 47 & 36 & 13 \\
\hline
\end{tabular}

Abbreviation: TPIs, trigger point injections.

Table 5 Length of time NSAIDs were held based on the type of procedure

\begin{tabular}{llll}
\hline Procedure & $\begin{array}{l}\text { Held on day of } \\
\text { procedure (\%) }\end{array}$ & $\begin{array}{l}\text { Held <I week prior } \\
\text { to the procedure (\%) }\end{array}$ & $\begin{array}{l}\text { Held }>\text { I week prior } \\
\text { to the procedure (\%) }\end{array}$ \\
\hline TPls & 71 & 17 & 9 \\
Medial branch block & 33 & 53 & 13 \\
Cervical epidural steroid injections & 9 & 63 & 27 \\
Lumbar epidural steroid injections & 12 & 61 & 26 \\
Joint injections & 47 & 44 & 8 \\
Peripheral nerve blocks & 51 & 38 & 10 \\
\hline
\end{tabular}

Abbreviations: NSAIDs, nonsteroidal anti-inflammatory drugs; TPIs, trigger point injections.

or the simplicity of implementing a single policy for all drugs (eg, holding all medications that could affect coagulation for 1 week, even when the half-life is 6 hours), or all procedures (eg, NPO). Lack of consistency could also reflect the range of training options for interventional pain, where some specialties may be more attuned to particular safety issues than others.

\section{NPO policies}

There are currently no established guidelines addressing NPO policies in patients receiving interventional pain procedures. Kennedy et $\mathrm{al}^{4}$ in 2013 examined $>4000$ subjects and found the incidence of vasovagal episodes to be $2.6 \%$ with a range of $0 \%$ in peripheral knee and shoulder injections to $5.1 \%$ in medial branch blocks. Significant bradycardia and hypotension are possible under these circumstances, including loss of consciousness. This scenario raises concerns for the risk of aspiration. Inadvertent subarachnoid local anesthetic during an epidural carries the risk of total loss of spinal and airway reflexes, again bringing into question the need for NPO guidelines. Similarly, procedures, such as stellate ganglion blocks and $\mathrm{C} 2$ medial branch nerve blocks, can be associated with intravascular injection and seizures with even very small volumes of local anesthetic. The presence of a full stomach under any of these circumstances could have catastrophic results. While $>90 \%$ of the respondents indicated that they have an NPO policy for patients undergoing procedures with sedation, the apparent lack of perceived risk in procedures without sedation is concerning.

\section{Sedation}

Our study demonstrated that variation exists in the use of sedation during various interventional pain procedures. The emphasis on patients' satisfaction in today's medical climate may fuel the use of sedation during these procedures, despite known risks, although in 2010, the American Society of Anesthesiology clearly stated that the majority of minor pain procedures, under most routine circumstances, do not require anesthesia care other than local anesthesia. ${ }^{5}$ The procedures that were specified include epidural steroid injections, trigger point injections (TPIs), epidural blood patches, sacroiliac joint injections, bursa injections, occipital nerve blocks, and facet injections. Studies have demonstrated an increased risk of neurological injury when patients received moderate or heavy sedation, and furthermore, the risk of spinal cord injury during cervical procedures has been shown to be higher in patients who received sedation and local or general anesthesia. ${ }^{6,7}$ Patients who are sedated may not be able to report pain or paresthesias in case of inadvertent spinal nerve or cord contact, thus significantly increasing the risk of injury. ${ }^{8}$ Despite these findings, $36 \%$ of the physicians in our survey used propofol when performing interventional spine procedures. Finally, administration of analgesics prior to diagnostic blocks (eg, medial branch nerve blocks) raises concerns about the validity of the results. It may be difficult to determine if the relief was due to the block or the opioid. ${ }^{9}$

Studies have also demonstrated lack of significant improvement in patient satisfaction when receiving sedation. In a retrospective audit, Diehn et $\mathrm{al}^{10}$ demonstrated that 
the majority of nonsedated patients rated their care as good $(15 \%)$, very good $(30 \%)$, or excellent $(51 \%)$, thus implying that high patient satisfaction rates can be achieved without the use of sedation. In addition, the authors stated that the rate of vasovagal reactions was low $(0.4 \%)$ in nonsedated patients. Other studies have confirmed similar low rates of vasovagal episodes in nonsedated patients undergoing epidurals. ${ }^{11}$ Furthermore, Cohen et al assessed the effect of sedation on the accuracy of diagnostic injections and patient satisfaction in a randomized, controlled, crossover study. They found that the use of sedation in diagnostic sacroiliac joint or sympathetic nerve blocks resulted in lower pain diary scores than those performed without sedation potentially increasing the risk of false-positive blocks. In contrast, they did not find differences in patient satisfaction between the sedation and nonsedation groups. ${ }^{12}$ Cucuzzella et $\mathrm{al}^{13}$ performed a survey of 500 patients who had received cervical, thoracic, lumbar, epidural, or facet injections and found that only $17 \%$ had requested sedation before the procedure if given a choice. In a follow-up study, Cucuzzella's group found that while slightly more than half of patients chose sedation, $93 \%$ of those who did not choose sedation were satisfied with their decision, while only $1.5 \%$ of them had wished that they had chosen sedation. ${ }^{14}$ Use of analgesic sedation for diagnostic medial branch nerve blocks could contribute to decreased pain post procedure, confounding the diagnostic value, and potentially increase the rate of subsequent unnecessary denervation procedures.

No systematic studies have been performed to establish relationships between various levels of sedation given for different interventional pain procedures and driving accidents after such procedures. Data do exist regarding fall risks, driving risks, and aspiration risks after various types of anesthesia for surgical procedures; however, whether the data are directly applicable to pain medicine interventions is a matter at least worth discussion.

It is clear from our survey that there is no consensus about the risk/benefit ratio associated with sedation for interventional pain procedures. This is reflected by the wide variation in the use of sedation in almost all the pain procedures mentioned. For example, $50 \%$ of the respondents used sedative agent in medial branch block. This may reflect an underappreciation of the risks, a lack of concern regarding the impact of sedation on the efficacy of diagnostic blocks, and/or the pressure to have high patient satisfaction scores. Hence, further study regarding the risks, benefits, and efficacy of sedation during interventional pain procedures in order to establish recommendations for appropriate, evidence-based best practices is critical.

\section{Driver policy}

There are no current guidelines for driver policy to help physicians practice evidence-based care. In our survey, a vast majority of physicians agreed on having a driver policy for procedures involving sedation. The response to procedures that were not done under sedation was varied, with as many as $40 \%$ physicians not requiring a driver after a procedure without sedation. These policies did not appear to differentiate between procedures that could be associated with hypotension or motor blockade in any meaningful fashion. The only procedure that stood out was trigger point injections, with the minority of respondents requiring a designated driver. While having a designated driver is often inconvenient to the patient and the driver and can be expensive due to lost work or accrued childcare expense, all procedures we surveyed carry risks that could incapacitate a patient. While there is no guideline regarding designated drivers for pain procedures, anesthesia guidelines for monitored anesthesia exist. Policies exist for other procedures involving sedation including colonoscopy. ${ }^{15}$ Having a driver policy is of utmost importance as certain pain procedures such as epidural steroid injection with local anesthetic and sacroiliac joint injections in patients with congenital sacral nonunions can cause inadvertent numbness and weakness in the leg, which obviously interferes with the ability to ambulate and drive safely. Sedation puts the patient at risk of driving under the influence, depending on the drugs used, and the time after administration to discharge. The wide variation in protocol, and the attendant risks associated with a lack of clear guidelines, raises concerns of patient safety as well as potential provider liability and medicolegal issues. This lack of consensus on various policies regarding periprocedural care is potentially dangerous and can lead to adverse events. This also reflects the varied perception of risk related to various components of procedural care. Until guidelines specific to the outpatient pain population are available, adherence to the anesthesia guidelines likely offers the safest, most defensible practice. ${ }^{15}$

\section{Steroids}

This survey also examined practices related to the frequency of use of corticosteroids in interventional pain procedures. Corticosteroids can be associated with numerous potential risks. Such side effects include weight gain, osteoporosis, hypertension, hyperglycemia, and adrenal suppression. A recent study by Goel et $\mathrm{al}^{16}$ suggests that $45 \%$ of the chronic pain patients who were being considered for a steroid injection as part of their treatment plan screened positive for the risk of adrenal suppression due to previous corticosteroid 
exposure from many sources including various injections, oral and inhaled steroids, and topical application prior to undergoing interventional pain procedures. Other studies have shown evidence of adrenal suppression with symptoms, such as low blood pressure, fatigue, and weight loss, following a single epidural steroid injection. Huebner et $\mathrm{al}^{17}$ showed depressed plasma cortisol levels even after 1-2 weeks after an epidural steroid injection. Jacobs et $\mathrm{al}^{18}$ found evidence of adrenal suppression at 3 weeks after a single epidural steroid injection. Prolonged suppression of adrenal function has also been found in healthy volunteers after intraarticular steroid injections. ${ }^{19}$ It is promising that most respondents $(83 \%)$ indicated that they wait at least $\geq 2$ weeks before reinjecting with steroid. However, $17 \%$ of the respondents waited $<2$ weeks before reinjecting with steroid. This practice may potentially place patients at risk for adrenal suppression as well as overt iatrogenic Cushing's syndrome, particularly with repeated injections. In addition, $42 \%$ of the respondents indicated they have often used steroids for TPIs, while a third of the responders used it for MBBs. This is in spite of the fact that there is no data to support the efficacy of corticosteroids for intramuscular injections and the theoretical risk of muscle atrophy. ${ }^{20}$ This routine use of steroids for these types of procedures may further place patients at unnecessary risk of adrenal suppression. It is clear that there is need for more research and the development of guidelines over the repeated use of steroids and the over utilization of steroids in procedures where they add limited benefit.

\section{Anticoagulants}

Finally, the survey also examined the length of time that anticoagulants were held prior to various pain procedures. Our survey demonstrated a variation in response to the amount of times that aspirin and NSAIDs were held prior to various procedures. The study was conducted prior to the recent release of the ASRA guidelines regarding the use of anticoagulants in pain procedures. ${ }^{1}$ It will be interesting to see if the recently published 2015 ASRA guidelines regarding neuroaxial blockade and regional nerve blocks will lead to a change in practice policies regarding anticoagulation. ${ }^{21}$ It is very possible that the preexisting anticoagulation guidelines from ASRA contributed to the almost universal positive response to the anticoagulation questions.

\section{Limitations}

This survey had some limitations. In an effort to limit the length of the survey and, hence, improve the response rate, specialty, or training of provider, the type of practice was not asked or linked to the use of sedation, NPO status, driving restrictions, or steroid utilization. Participants were not asked about which specific type of NSAIDs was held before a procedure. Discontinuation of anticoagulants was asked in regard to all procedures and was not asked in relation to a particular procedure. It would have been helpful to determine if actual dose of steroid administered influenced the number and timing of injections, as well. Length of NPO policy and relation to individual types of procedures were not asked.

\section{Conclusion}

Currently, there are few published guidelines to assist interventional pain physicians in their practice. While the number of responses to the survey is limited and may not be applicable to all pain medicine interventional practices, we did identify a wide variation in the current practice among physicians regarding sedation, NPO status, steroid administration, management of other medications that could impact coagulation such as NSAIDs, herbal medications, and SSRIs, and the need for designated drivers. Establishment of a reporting database for adverse outcomes would assist in identifying the actual risk of these various practices. There is an obvious need for evidence-based best practice guidelines for these aspects of interventional pain care to improve patient safety and minimize the risk of adverse events.

\section{Disclosure}

The authors report no conflicts of interest in this work.

\section{References}

1. Narouze S, Benzon HT, Provenzano DA, et al. Interventional spine and pain procedures in patients on antiplatelet and anticoagulant medications: guidelines from the American Society of Regional Anesthesia and Pain Medicine, the European Society of Regional Anaesthesia and Pain Therapy, the American Academy of Pain Medicine, the International Neuromodulation Society, the North American Neuromodulation Society, and the World Institute of Pain. Reg Anesth Pain Med. 2015;40(3):182-212.

2. ASAHQ [webpage on the Internet]. Statement on Anesthetic Care During Interventional Pain Procedures for Adults. Committee of Origin. American Society of Anesthesiologists - Standards \& Guidelines. Pain Medicine. 2016. Available from: https://www.asahq.org/quality-andpractice-management/standards-and-guidelines. Accessed June 8, 2016.

3. Apfelbaum JL, Silverstein JH, Chung FF, et al; American Society of Anesthesiologists Task Force on Postanesthetic Care. Practice guidelines for postanesthetic care: an updated report by the American Society of Anesthesiologists Task Force on Postanesthetic Care. Anesthesiology. 2013;118(2):291-307.

4. Kennedy D, Schneider BJ, Casey EK, Rittenberg JD, Lento PH, Smuck M. Vasovagal rates in fluoroscopically guided interventional procedures: a study of over 8,000 injections. Pain Med. 2013;14(12):1854-1859.

5. ASAHQ. Statement on Anesthetic Care during Interventional Pain. (n.d.). Available from: http://www.asahq.org/ /media/Sites/ASAHQ/ Files/Public/Resources/standards-guidelines/statement-on-anestheticcare-during-interventional-pain-procedures-for-adults.pdf. Accessed August 13, 2016. 
6. Fitzgibbon DR, Rathmell JP, Michna E, Stephens LS, Posner KL, Domino KB. Malpractice claims associated with medication management for chronic pain. Anesthesiology. 2010;112(4):948-956.

7. Rathmell JP, Michna E, Fitzgibbon DR, Stephens LS, Posner KL, Domino KB. Injury and liability associated with cervical procedures for chronic pain. Anesthesiology. 2011;114(4):918-926.

8. Gajraj NM. Avoid excessive sedation during cervical injections. Anesthesiology. 2005;102(4):869.

9. Smith HS, Colson J, Sehgal N. An update of evaluation of intravenous sedation on diagnostic spinal injection procedure. Pain Physician. 2013;16(2 suppl):SE217-SE228.

10. Diehn FE, Geske JR, Amrami KK, et al. An audit of transforaminal epidural steroid injections without sedation: low patient dissatisfaction and low vasovagal rates. Pain Med. 2013;14(7):994-998.

11. Trentman TL, Rosenfeld DM, Seamans DP, Hentz JG, Stanek JP. Vasovagal reactions and other complications of cervical vs. lumbar translaminar epidural steroid injections. Pain Pract. 2009;9(1):59-64.

12. Cohen SP, Hameed H, Kurihara C, et al. The effect of sedation on the accuracy and treatment outcomes for diagnostic injections: a randomized, controlled, crossover study. Pain Med. 2014;15(4):588-602.

13. Cucuzzella TR, Delport EG, Kim N, Marley J, Pruitt C, Delport AG. A survey: conscious sedation with epidural and zygapophyseal injections: is it necessary? Spine J. 2006;6(4):364-369.
14. Kim N, Delport E, Cucuzzella T, et al. Is sedation indicated before spinal injections? Spine. 2007;32(25):E748-E752.

15. Standards of Practice Committee, Faigel DO, Eisen GM, et al. Preparation of patients for GI endoscopy. Gastrointest Endosc. 2003; 57(4):446-450.

16. Goel AP, Nguyen VH, Hamill-Ruth R. Use of a risk-stratification tool in identification of potential adrenal suppression preceding steroid injection therapy in chronic pain patients. Pain Med. 2015;16(12): 2226-2234.

17. Huebner T, Guido KS, Christoph H, Helmut RG. Prevalence of impaired adrenal function after epidural steroid application for low back pain. Anesthesiology. 2004;101:A955.

18. Jacobs S, Pullan PT, Potter JM, Shenfield GM. Adrenal suppression following extradural steroids. Anesthesia. 1983;38(10):953-956.

19. Habib GS. Systemic effects of intra-articular corticosteroids. Clin Rheumatol. 2009;28(7):749-756.

20. Malanga GA, Cruz Colon EJ. Myofascial low back pain: a review. Phys Med Rehabil Clin N Am. 2010;21(4):711-724.

21. Neal JM, Barrington MJ, Brull R, et al. The second ASRA practice advisory on neurologic complications associated with regional anesthesia and pain medicine: executive summary 2015. Reg Anesth Pain Med. 2015;40(5):401-430. 


\section{Supplementary materials}

1. Have you, or does your practice deliver any sedative agents (benzodiazepines, opioids, diphenhydramine, propofol, etc.) to your patients prior to or during procedures?

Y Yes

No

2. If so, which procedures do you routinely provide sedation for?

\begin{tabular}{lll}
\hline & Yes & No \\
TPI (trigger point injections) & $\bigcirc$ & 0 \\
Regional (Ilioinguinal/iliohypogastric, femoral, supraclavicular, etc) & $\bigcirc$ & 0 \\
Peripheral nerve blocks (occipital, supraorbital, etc) & 0 & 0 \\
ESI (epidural steroid injections) & $\bigcirc$ & 0 \\
Medial branch nerve blocks & 0 & 0 \\
SI Joint (sacroiliac) & 0 & 0 \\
RFA (radiofrequency ablation) & 0 & 0 \\
Fluoro guided plexus blocks & 0 & 0 \\
Intraarticular injections & 0 & 0 \\
\hline
\end{tabular}

3. What types of sedative medications are utilized?

\begin{tabular}{lll}
\hline & Yes & No \\
Opioids & 0 & 0 \\
Benzodiazepines & 0 & 0 \\
Propofol & 0 & 0 \\
Antihistamines & 0 & 0 \\
Alpha 2 agonist & 0 & 0 \\
NMDA antagonist & 0 & 0 \\
\hline
\end{tabular}

Other (please specify)

4. Do you have an NPO status policy for patients undergoing procedures who do not receive sedation?
Y Yes
○ No

5. Do you have an NPO status policy for patients receiving sedation when undergoing procedures?

$\bigcirc$ Yes

○ No

6. Please indicate which of the following matches your driver policy for a patient NOT receiving sedation for the following procedures:

Epidural injections with local anesthetic

Epidural injections WITHOUT local anesthetic

Diagnostic medial branch nerve blocks

SI joint injections

Trigger point injections

Regional nerve blocks

Plexus/ganglion blocks

\begin{tabular}{lll} 
Designated Driver & Public Transportation & Can drive self \\
0 & 0 & 0 \\
0 & 0 & 0 \\
0 & 0 & 0 \\
0 & 0 & 0 \\
0 & 0 & 0 \\
0 & 0 & 0 \\
0 & 0 & 0 \\
\hline
\end{tabular}


7. Please indicate which of the following matches your driver policy for a patient RECEIVING sedation for the following procedures:

\begin{tabular}{llll}
\hline & Designated Driver & Public Transportation & Can drive self \\
Epidural injections with local anesthetic & 0 & 0 & 0 \\
Epidural injections WITHOUT local anesthetic & 0 & 0 & 0 \\
Diagnostic medial branch nerve blocks & 0 & 0 & 0 \\
SI joint injections & 0 & 0 & 0 \\
Trigger point injections & 0 & 0 & 0 \\
Regional nerve blocks & 0 & 0 & 0 \\
Plexus/ganglion blocks & 0 & 0 & 0 \\
\hline
\end{tabular}

8. When administering steroids, is there a minimum time interval required between injections?

$\bigcirc$ No

$\bigcirc$ Yes - please specify interval:

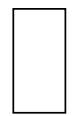

9. When administering steroids, is there a maximum number of doses (or cumulative amount in $\mathrm{mg}$ ) per year?

$\bigcirc$ No

Yes - please specify number of doses and/or cumulative amount:

10. Please indicate for which procedures steroids are utilized (if at all):

\begin{tabular}{llll}
\hline & Never & Rarely & Often \\
\hline TPI & $\bigcirc$ & 0 & $\bigcirc$ \\
Regional blocks & 0 & 0 & 0 \\
Peripheral nerve blocks & 0 & 0 & 0 \\
Interlaminar ESI & $\bigcirc$ & 0 & 0 \\
Transforaminal ESI & 0 & 0 & 0 \\
Medial Branch nerve blocks & 0 & 0 & 0 \\
Intraarticular (including facet) injections & $\bigcirc$ & 0 & 0 \\
SI joint injections & 0 & 0 & 0 \\
RFA & 0 & 0 & 0 \\
Plexus/Ganglion blocks & $\bigcirc$ & 0 & 0 \\
\hline
\end{tabular}

Other (please specify)

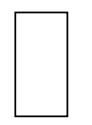

11. Do you require your patients to hold their ASA prior to procedures?

$\bigcirc$ Yes

No 
12. How long do you require ASA to be held prior to the following procedures?

\begin{tabular}{llll}
\hline & Day of & Less than 1 week & Greater than 1 week \\
TPI & 0 & 0 & 0 \\
Medial Branch Blocks & $\bigcirc$ & 0 & 0 \\
CESI (cervical epidural steroid injection) & 0 & 0 & 0 \\
LESI (lumbar epidural steroid injection) & 0 & 0 & 0 \\
Joint injections & $\bigcirc$ & 0 & $\bigcirc$ \\
Peripheral nerve blocks & 0 & 0 & 0 \\
\hline
\end{tabular}

13. Do you require your patients on NSAIDs to hold their medication prior to procedures?

O Yes

○ No

14. How long do you require NSAIDs to be held prior to the following procedures?

\begin{tabular}{|c|c|c|c|}
\hline & Day of & Less than 1 week & Greater than 1 week \\
\hline TPI & ○ & 0 & $\bigcirc$ \\
\hline Medial Branch Blocks & $\bigcirc$ & $\bigcirc$ & $\bigcirc$ \\
\hline CESI & $\bigcirc$ & $\bigcirc$ & $\bigcirc$ \\
\hline LESI & ○ & O & O \\
\hline Joint injections & 0 & $\bigcirc$ & $\bigcirc$ \\
\hline
\end{tabular}

15. Do you require patients on other forms of anticoagulation to hold their medications prior to procedures? (ie, Heparin, Lovenox, Warfarin)

Yes

No

16. Are there any other classes of medications you require patients to hold prior to a procedure (ie, SSRIs, anticonvulsants, herbal medications)
$\bigcirc$ Yes
No
$\bigcirc$ Please specify medications if yes.

Abbreviations: NSAIDS, nonsteroidal anti-inflammatory drugs; ASA, American Society of Anesthesiologists.

\section{Publish your work in this journal}

The Journal of Pain Research is an international, peer reviewed, open access, online journal that welcomes laboratory and clinical findings in the fields of pain research and the prevention and management of pain. Original research, reviews, symposium reports, hypothesis formation and commentaries are all considered for publication.
The manuscript management system is completely online and includes a very quick and fair peer-review system, which is all easy to use. Visit http://www.dovepress.com/testimonials.php to read real quotes from published authors. 